\title{
A REVIEW OF ACHIEVEMENTS OF THE NATIONAL SCHISTOSOMIASIS CONTROL PROGRAM IN MIDDLE AND UPPER EGYPT AREAS
}

\author{
SAMIR NASSIF
}

\author{
Endenuic Diseases Control Department, Ministry of Health, Cairo, Egypt
}

\begin{abstract}
In Egypt the "national schistosomiasis control program" was formulated to control transmission by reduction of prevalence and intensity of current infections, and thereby achieve an acceptable level of schistosomiasis disease control. The program was implemented foremost in Middle Egypt (1977) and Upper Egypt (1980), collectively extending $800 \mathrm{~km}$ alongside of the River Nile and accomodate about 10.5 million people. Schistosoma haematobium has been essentially the prevailing species infection in both areas. The strategy of control entailed both area-wide mollusciciding with niclosamide, and selective population chemotherapy with metrifonate. Evaluation in 1986 showed that prevalence dropped from pre-control $29.4 \%$ in Middle Egypt and $26.3 \%$ in Upper Egypt to 6\% and $7.8 \%$ respectively, together with a remarkable drop of infections among children. Also mean intensity attained low levels consistent of low grade infections. It is evident therefore that in these areas where an enhancement of schistosomiasis infections had been anticipated the employment of the twofold strategy effected a state of low-prevalence/lowintensity signifying a lowered reservoir of infection and a substantial interference with the potentials of transmission.
\end{abstract}

In Egypt schistosomiasis (bilharziasis) continues as a leading public health problem due to widespread prevalence, serious morbidity and a significant implication of the national economy. The problem has been steadily aggravating during late years on account of implementation of energetic irrigation and drainage projects associated with land reclamation schemes that entailed construction of an elaborate network of canals and drains, nevertheless preventive environmental measures were not adequately incorporated.

Campaigns for control of schistosomiasis in Egypt date back to 1922 and essentially employed chemotherapy or snail control measures. The latest campaign "the national schistosomiasis control program" was formulated on account of a rather alarming situation as regards a flare of infections among the rural population. The program aimed to control transmission by reduction of prevalence and intensity of current infections, and thereby achieve an acceptable schistosomiasis disease control beyond a public health problem. For implementation Egypt was subdivided into 10 "control areas" sharing common geographic boundries, environemental features and/or source of irrigation. Priority was assigned foremost in Middle Egypt in 1977 and in Upper
Egypt in 1980, justified by: 1) an enhanced prevalence of the prevailing schistosomiasis haematobium on account of a thorough changeover of the system of irrigation from basin to perennial; 2) implementation of vast water development projects in both areas; and 3) the areas had been under the iminent threat of invasion by Schistosoma mansoni species infections prevailing in the Nilo Delta, forasmuch as Biomphalaria snails lately established habitat in the main water courses.

\section{AREA AND POPULATION}

Collectively Middle Egypt and Upper Egypt extend for almost $800 \mathrm{~km}$ alongside of the River Nile and cover an area of 2.2 million feddans (acres) of cultivated land, and a population of 10.5 million accomodated in 7 governorate at 1,267 villages. The total length of water courses, i. e., canals and drains, is about 100,000 km (Fig. 1).

\section{METHODS}

The strategy comprized employment of a combination of area-wide mollusciciding and selective population chemotherapy simultaneously. 


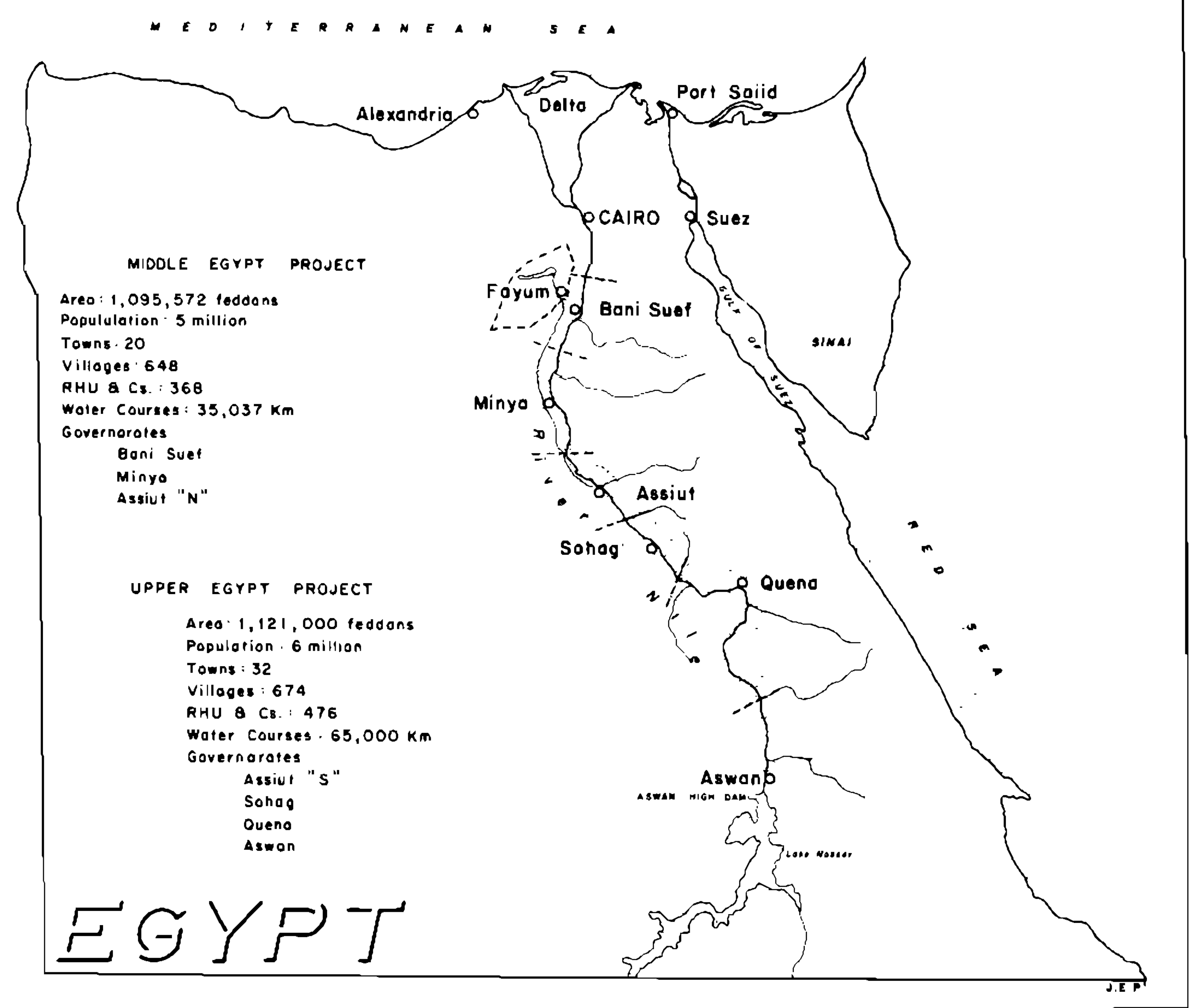

Fig. 1: map showing Middle and Upper Egypt.

A - Area-wide (blanket) mollusciciding entailed application of niclosamide at sites of origin of main canals to achieve a concentration of 1.2 p.p.m. for 8 hours. The applications were phased: 3 times/year during the "active intervention" for 3 years, twice/year during "consolidation" for 3 years, and maintain a single Summer application each year thereafter. Surveillance and focal mollusciciding of static waterbodies have been undertaken periodically as well. Mollusciciding has been carried out by "snail units and inspectorates", 215 in Middle Egypt and 296 in Upper Egypt.

B - Selective population chemotherapy, based on perpetuation of a total population screening coverage every year; school children handled as a target population have been examined and cases treated twice during each school year. Metrifonate (Bilarcil) $10 \mathrm{mg} / \mathrm{kg}$ body weight every 2 weeks for 3 doses had been the regimen adopted for cases. However praziquantel $40 \mathrm{mg} / \mathrm{kg}$ body was innovated in 1983 to supplement chemotherapy of S. haematobium among the overall population at villages that maintained a higher prevalence than the average for the district, and at the villages where $S$. mansoni cases showed, as well as exclusively for cases among school children at all villages. Delivery of chemotherapy had been approached horizontally by integration among services of basic health care undertaken by the "rural health units and centers" (R.H.U.), 347 in Middle Egypt and 476 in Upper Egypt, each serving a population of about 5,000 .

Evaluation both "self" and "independent" had been an integral component of the control campaign and paralled all control procedures.

\section{RESULTS}

The results are shown on Tables I and II. 
TABLE I

Middle Egypt Project - Prevalence, S. haematobium, 1977-1986

\begin{tabular}{|c|c|c|c|c|c|}
\hline Year & & $\begin{array}{c}\text { Outpatients } \\
\text { R.H.U.s }\end{array}$ & $\begin{array}{l}\text { Sample } \\
\text { surveys }\end{array}$ & $\begin{array}{l}\text { School } \\
\text { children }\end{array}$ & COHORT \\
\hline \multirow[t]{2}{*}{$1977 / 78$} & Examined & $2,745,769$ & 27,405 & 213,179 & 27,405 \\
\hline & S. haematobium \% & 29.4 & 29.4 & 23.5 & 29.4 \\
\hline \multirow[t]{2}{*}{1979} & Examined & $1,316,637$ & 302,272 & 219,612 & 21,986 \\
\hline & S. haematobium \% & 19.5 & 16.1 & 21.5 & 16.0 \\
\hline \multirow[t]{2}{*}{1980} & Examined & $1,135,578$ & 211,630 & 212,125 & 22,840 \\
\hline & S. haematobium \% & 16.4 & 16.4 & 24.4 & 11.0 \\
\hline \multirow[t]{2}{*}{1981} & Examined & $1,373,982$ & 396,401 & 277,841 & 22,183 \\
\hline & S. haematobium \% & 16.3 & 14.0 & 20.9 & 11.6 \\
\hline \multirow[t]{2}{*}{1982} & Examined & $1,603,232$ & 730,289 & 281,112 & 23,386 \\
\hline & S. haematobium \% & 15.4 & 13.4 & 21.2 & 11.4 \\
\hline \multirow[t]{2}{*}{1983} & Examined & $1,466,056$ & 627,125 & 338,657 & 21,189 \\
\hline & S. haematobium \% & 12.1 & 10.5 & 21.6 & 9.9 \\
\hline \multirow[t]{2}{*}{1984} & Examined & 794,934 & 801,964 & 378,200 & 20,667 \\
\hline & S. haematobium \% & 12.5 & 9.1 & 17.1 & 9.1 \\
\hline \multirow[t]{2}{*}{1985} & Examined & 833,369 & 854,461 & 411,555 & 21,642 \\
\hline & S. haematobium $\%$ & 10.1 & 7.4 & 14.2 & 6.6 \\
\hline \multirow{2}{*}{1986} & Examined & 782,605 & 926,178 & 477,620 & 24,516 \\
\hline & S. haematobium \% & 8.9 & 6.0 & 14.2 & 5.5 \\
\hline
\end{tabular}

Results of examinations:

Outpatients, R.H.U.s, at all villages.

Stratificd random sample surveys, each $5-10 \%$ of the total households, at all villages.

School children examinations, at all villages.

Fixed sample "COHORT" surveys, at index villages.

TABLE II

Upper Egypt Project - Prevalence, S. haematobium, 1980-1986

\begin{tabular}{llcccc}
\hline Year & & $\begin{array}{c}\text { Outpatients } \\
\text { R.H.U.s }\end{array}$ & $\begin{array}{c}\text { Sample } \\
\text { surveys }\end{array}$ & $\begin{array}{c}\text { School } \\
\text { children }\end{array}$ & COHORT \\
\hline 1980 & Examined & $1,726,222$ & 180,210 & 306,859 & 180,612 \\
& S. haematobium \% & 26.7 & 26.3 & 30.9 & 25.8 \\
1981 & Examined & 839,418 & 657,681 & 440,631 & 70,786 \\
& S. haematobium \% & 21.1 & 23.6 & 29.0 & 17.9 \\
1982 & Examined & $1,721,935$ & 830,994 & 494,799 & 69,744 \\
& S. haematobium \% & 20.4 & 17.8 & 28.3 & 71,299 \\
1983 & Examined & $2,583,594$ & $1,222,236$ & 527,532 & 9.4 \\
& S. haematobium \% & 16.0 & 13.4 & 25.4 & 37,846 \\
1984 & Examined & 801,143 & 868,216 & 555,782 & 13.6 \\
& S. haematobium \% & 15.5 & 12.3 & 23.1 & 8.126 \\
1985 & Examined & 772,939 & $1,104,722$ & 600,269 & 8.8 \\
& S. haematobium \% & 15.9 & 11.4 & 22.6 & 8,426 \\
& Examined & 734,442 & $1,092,273$ & 644,194 & 8.4 \\
\hline
\end{tabular}

Results of examinations:

Outpatients, R.H.U.s, at all villages.

Stratified random sample surveys, each $5-10 \%$ of the total households, at all villages.

School children examinations, at all villages.

Fixed sample "COHORT" surveys, at index villages. 
Pre-control: stratified random sample surveys denoted a prevalence $29.4 \%$ in Middle Egypt, and $26.3 \%$ in Upper Egypt. Although data about the intensity of the infections were not thoroughly comprehensive there had been ample information indicating that in both areas average ova cuunts outranked a geometric mean 200/10 ml urine.

Post-control: evaluation in 1986 showed that prevalence of $S$. haematobium in Middle Egypt dropped to $6 \%$ (reduction: $79.6 \%$ ), and in Upper Egypt to $7.8 \%$ (reduction: $70.3 \%$ ). Intensity dropped to 15.9 ova in Middle Egypt and 20.9 in Upper Egypt. Incidence of new infections measured as conversion among subsamples of "negative" school children followed after a year; in Middle Egypt dropped from $27 \%$ in October 1978 to $9 \%$ in Oct. 1985 , and in Upper Egypt from $37.5 \%$ in Oct. 1980 to $12.5 \%$ in Oct. 1985.

\section{DISCUSSION}

In both control areas where an aggravation of the already enhanced $S$. haematobium infections had been anticipated the employment of the twofold strategy effected remarkable issues as had been evidenced by a significant reduction of all parameters of the infection. It is manifest that $S$. haematobium infections thereby attained a state of low prevalence-low intensity consistent of a lowered reservoir of infection, and expectedly an adequate morobidity control. However transmission could not be climinated a substantial interference with its potentials was achieved; persistence of transmission at that rather limited caliber was explained as an issue of habitual re-infections, perseverence of behaviour and life-style and inadequate sanitation in the village, besides the impact of implementation of water development schemes in the areas. Nevertheless the decline of prevalence of $S$. haematobium infections in Middle Egypt was not symmetrical but fluctuated in accordance with the varied bulk and degree of perfection at which the control measures were cmployed. Lagging of the prevalence curve (Fig. 2) during the "consolidation phase" 1980-1982 coincided with a sizeable reduction of mollusciciding, both in accordance with the plan of operation and on account of incidental logistic and operational problems and a meantime imperfected screcning coverage. However the competence of metrifonate to act "single handed" as the

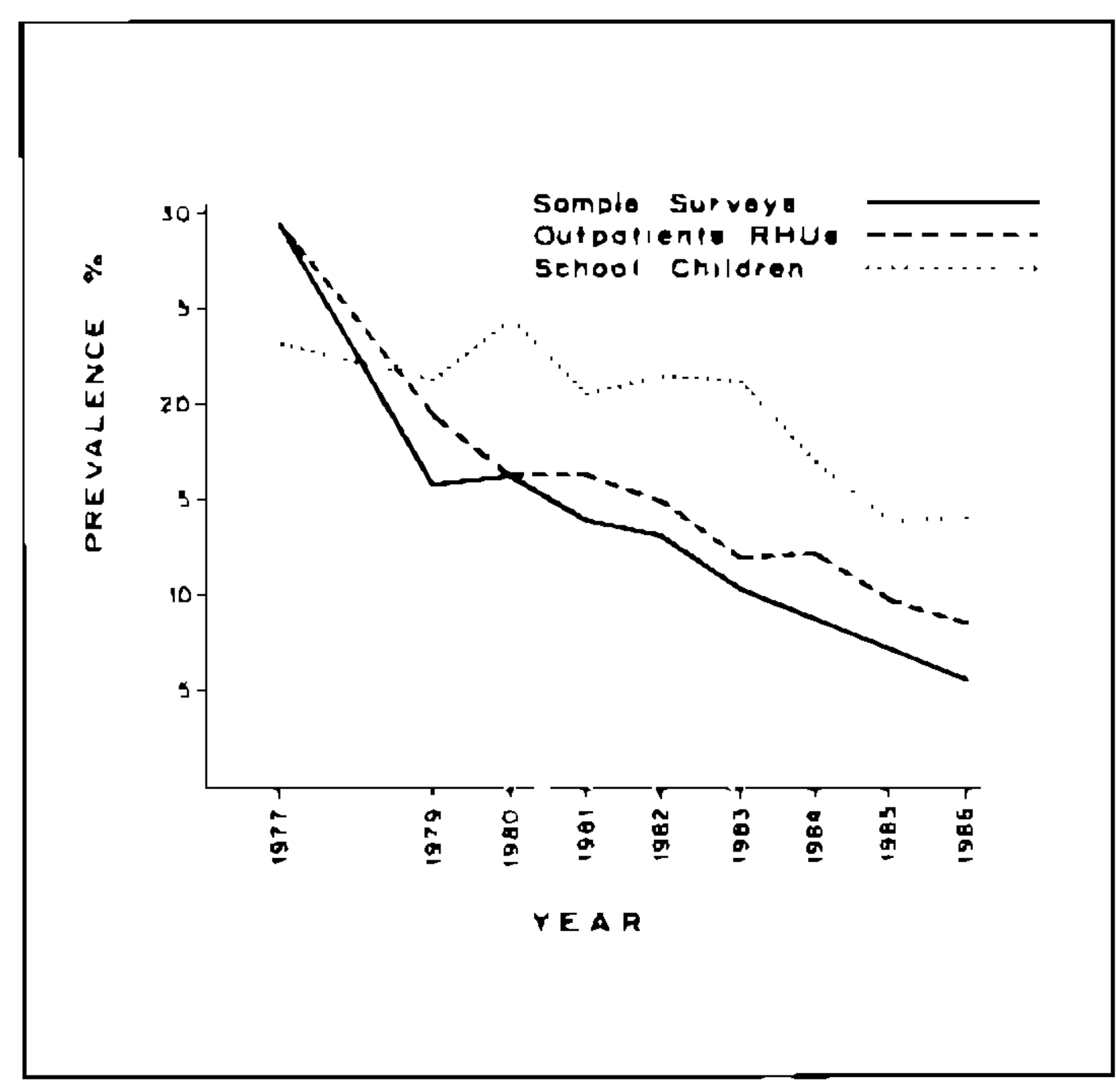

Fig. 2: Middle Egypt project - Prevalence. Schistosoma hoematobium, 1977-1986.

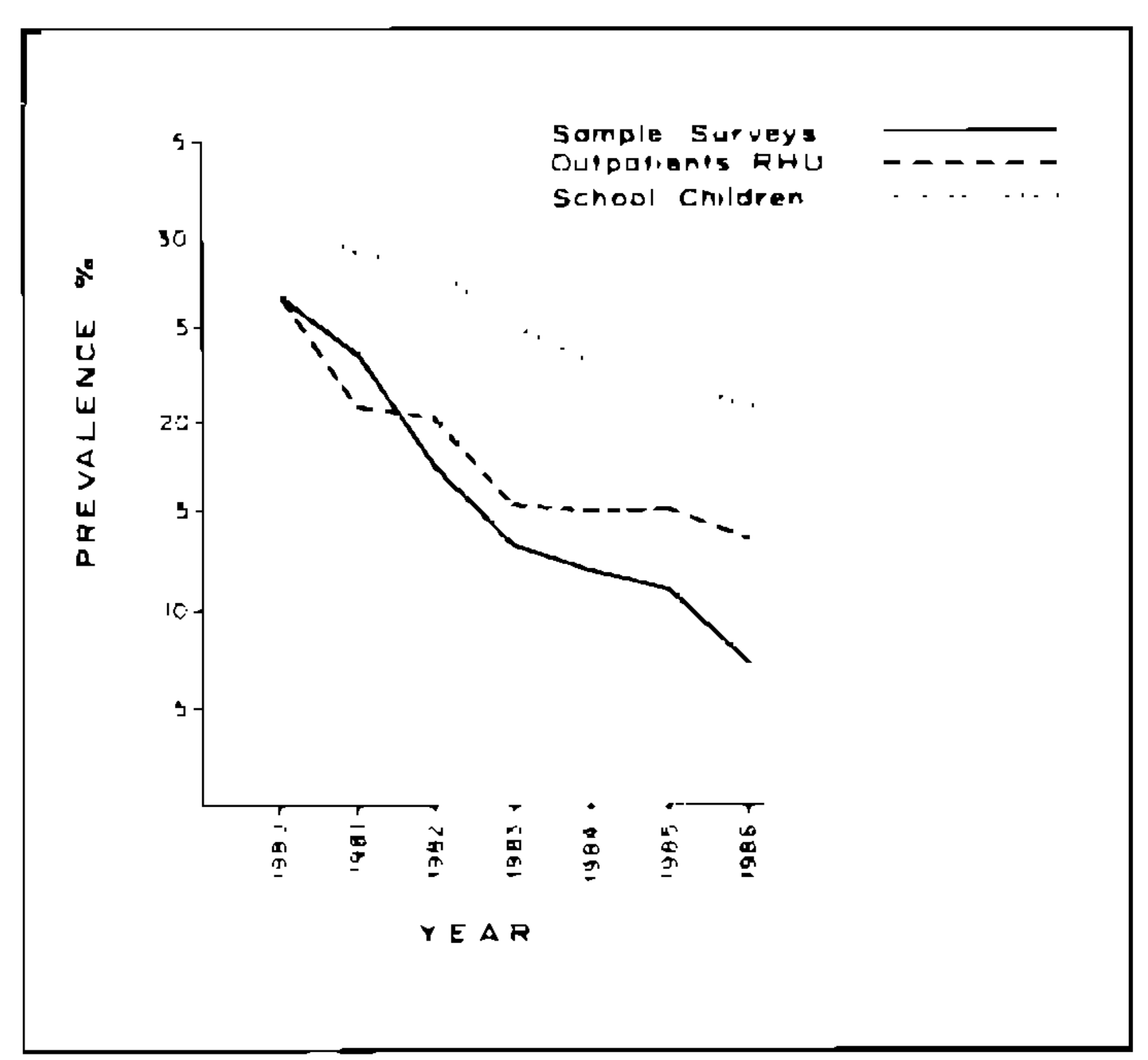

Fig. 3: Upper Egypt project - Prevalence, Schistosoma haematobium, 1980-1986.

tool of chemotherapy became questionable in view of a growing lack of acceptance, regimen in 3 doses and a significant failure rate. Eventually the innovation of praziquantel to supplement chemotherapy proved a most rational amendment to the campaign that issued a significant uplift of its potentials, and adapted its objectives to "morbidity control" as a more feasible goal than transmission control. Besides the employment of praziquantel almost eliminated problems of compliance, acceptance and coverage, and 
TABLE III

The analysis of cost in Middle Egypt control project, 1977-1984

Total cost of control $=$ L. E. 26 million - Allocations.

\begin{tabular}{lccc}
\hline & Snail control & Chemotherapy & Total \\
\hline Salaries and incentives & $23 \%$ & $86.4 \%$ & $42.6 \%$ \\
Molluscicides & 71 & 11.3 & 49 \\
Chemotherapeutics & & & 3.5 \\
Vehicles & & $30.9 \%$ & 4.1 \\
Current cxpenses & $69.1 \%$ & $100.0 \%$ \\
\hline Total & & 30.8 \\
\hline
\end{tabular}

Obs.:

- The mean expenditure/year: L. E. 3,259,983.

- The per capita cost of the project: L. E. 0.64 ( $=64$ piastres).

- The cost of control per person at risk: L. E. 0.76 .

-. Sources of finance: - Ministry of Health, in local currency: 63\%; - Loans, in hard currency: $37 \%$.

probably effected a considerable depletion of the reservoir of infection in man. Consequently the prevalence of $S$. haematobium among school children that continued refractory for 7 years at a range $21.24 \%$ dropped to $14.2 \%$ in 1985. Simultaneously a system "selective-area mollusciciding" was advocated to replace area wide applications and to economize on their cost which exhausted almost $70 \%$ of the total cost of control (Table III). The system depended on current epidemiological trends and periodic snail surveillance data, and entailed dispensing niclosamide in secondary canals or focally at sites showing high prevalence and/or dense snail population.

The campaign also issucd remarkably as regards "transitory fencing" of the areas against flare of $S$. mansoni infections by virtue of repeated snail surveillance, snail control and active case finding programs.

\section{ACKNOWLEDGEMENT}

I am indebted to all staff of the Endemic Diseases Control, in the field and office who, by dedication, competence and enthusiasm, were able to accomplish the successful campaign against the notorius disease. I feel grateful to my colleague Dr S. El Hak for his advice.

\section{REFERENCE}

ABDALLAH, A.; SAIf: M. \& KOURA, M., 1975. The role of chemotherapy in the control of schistosomiasis, experience in Egypt. Brasilia Medica, 11:12.

ABDEL WAHAB, M. F., 1982. Schistosomiasis in Egypt. CRC Press Inc., BOCA Raton, Florida.

AYAD, N., 1976. Snail control. Egyptian J. Bilharziasis, $3: 102$.

DAVIS, A., 1973. Chemotherapy in control of schistosomiasis. WHO publications. Karger, Baseland University Press, Baltimore.

EL HAK, S., 1984. Schistosomiasis in Egypt. 11 th Congress of Tropical Medicine and Malaria, Calgary, Canada.

JORDAN, P. \& WEBBE, G., 1982. Schistosomiasis. epidemiology, treatment and control. William Heinmann Medical Books Ltd., London.

MOUSSA, A. H.; AYAD, N. \& ATTA, A., 1968. Schistosomiasis control measures. J. Public Health Assoc.: 43.

NASSIF, S. \& EL KALOUBY, A., 1984. The role of chemotherapy of schistosomiasis in integrated control. Symposium, TBI, Cairo.

NASSIF, S., 1984. Schistosomiasis control in Middle Figypt and Upper Egypt areas. 11 th Congress for Trop. Med. \& Malaria, Calgary, Canada.

NASSIF, S., 1985. Impact and complication of chemotherapy of schistosomiasis. Workshop on recent advances in the epidemiologic strategies for schistosomiasis control. WHO, Wad Medani, Sudan.

NASSIt;, S., 1986. National schistosomiasis control program. Middle Egypt and Upper Egypt projects. Progress reports, Ministry of Health, Egypt.

Report of an independent evaluation mission on The National Bilharzia Control Program in Egypt, 1985. Trans. R. Soc. Trop. Med. Hyg., 81 (supplement): 1-57.

ZFMIETY, O., 1979. A review of the National Schistosomiasis Control Program. Schistosomiasis. Symposium, Cairo, 1979. 